\title{
$\beta$-Amyloid-Mediated Inhibition of NMDA Receptor- Dependent Long-Term Potentiation Induction Involves Activation of Microglia and Stimulation of Inducible Nitric Oxide Synthase and Superoxide
}

\author{
Qinwen Wang, ${ }^{1}$ Michael J. Rowan, ${ }^{2}$ and Roger Anwyl ${ }^{1}$ \\ Departments of ${ }^{1}$ Physiology and ${ }^{2}$ Pharmacology and Therapeutics, Trinity College, Dublin 2, Ireland
}

\begin{abstract}
The mechanisms underlying the inhibition of long-term potentiation (LTP) induction by amyloid $\beta$-peptide $(\mathrm{A} \beta)$ were investigated in the medial perforant path of the rat and mouse dentate gyrus in vitro. Evidence is presented in this study that the $A \beta$-mediated inhibition of LTP induction involves activation of microglia and production of reactive oxygen and nitrogen species. In control slices, $A \beta$ strongly inhibited induction of NMDA receptor-dependent (NMDAR-dependent) LTP, although not induction of NMDAR-independent LTP or long-term depression (LTD). The inhibition of NMDAR-dependent LTP was prevented by minocycline, an agent that prevents activation of microglia. The involvement of inducible nitric oxide synthase (iNOS) was shown by the inability of A $\beta$ to inhibit LTP induction in iNOS knock-out mice and also by the ability of two iNOS inhibitors, aminoguanidine and $1400 \mathrm{~W}$, to prevent the $\mathrm{A} \beta$-mediated inhibition of LTP induction. The $\mathrm{A} \beta$-mediated inhibition of LTP induction also was prevented by the superoxide scavenger superoxide dismutase applied together with catalase. Evidence for involvement of superoxide in the action of $\mathrm{A} \beta$ on LTP induction was shown by the ability of an inhibitor of NADPH oxidase to prevent the A $\beta$-mediated inhibition of LTP induction. The study thus provides evidence that the A $\beta$ mediated inhibition of LTP induction involves an inflammatory-type reaction in which activation of microglia results in the production of nitric oxide and superoxide and thence possibly peroxynitrite, a highly reactive oxidant.
\end{abstract}

Key words: amyloid $\beta$-protein; LTP; dentate gyrus; microglia; inducible nitric oxide; superoxide; caspases

\section{Introduction}

Alzheimer's disease (AD) is characterized by the presence of senile plaques composed of deposits of amyloid $\beta$-peptide $(\mathrm{A} \beta)$, a cleavage product of $\beta$-amyloid precursor protein (APP). A $\beta$ has been strongly implicated as a causal factor in $\mathrm{AD}$, with evidence that $\mathrm{A} \beta$-induced dysfunction of synaptic plasticity contributes to the early memory loss that precedes neuronal degeneration (Small et al., 2001; Selkoe, 2002). We have shown previously that synthetic $A \beta$ inhibits one form of synaptic plasticity, long-term potentiation (LTP), in studies in the hippocampus in vivo (Cullen et al., 1997) and also that soluble cell-derived naturally secreted human $\mathrm{A} \beta$ acutely inhibits the induction of LTP in vivo and in vitro in the hippocampus (Walsh et al., 2002; Wang et al., 2004). The A $\beta$-mediated block of LTP has been confirmed now in other investigations (Lambert et al., 1998; Itoh et al., 1999; Chen et al., 2000; Stephan et al., 2001; Vitolo et al., 2002; Raymond et al., 2003). Little is known about the mechanisms involved in $\mathrm{A} \beta$ mediated inhibition of LTP, although in a recent study we have demonstrated a necessity for the activation of certain kinases

Received Jan. 21, 2004; revised May 25, 2004; accepted May 25, 2004.

This work was supported by grants from the Wellcome Trust and the Science Foundation of Ireland.

Correspondence should be addressed to Roger Anwyl, Department of Physiology, Trinity College, Dublin 2, Ireland. E-mail: ranwyl@tcd.ie.

DOI:10.1523/JNEUROSCI.0233-04.2004

Copyright $\odot 2004$ Society for Neuroscience $\quad$ 0270-6474/04/246049-08\$15.00/0 including c-Jun N-terminal kinase (JNK), p38 MAP kinase (p38 MAPK), and cyclin-dependent kinase 5 (Cdk5) in the $\mathrm{A} \beta$ mediated inhibition of LTP (Wang et al., 2004). In addition, $\mathrm{A} \beta$-mediated inhibition of LTP was found to be reversed by rolipram and forskolin, agents that enhance cAMP signaling (Vitolo et al., 2002).

In the present studies, we have explored further the mechanisms underlying the inhibition of LTP induction by A $\beta$. Strong evidence indicates that oxidative stress plays an important role in the pathophysiology of $\mathrm{AD}$, involving the production of free radicals and inflammatory agents (Akiyama et al., 2000). This inflammation in the brain involves mainly the activity of microglial and astroglial cells that secrete a host of factors including cytokines, nitric oxide, and reactive oxygen species that impact on neurons to induce degeneration (Akiyama et al., 2000). We investigated the involvement of microglia and reactive nitrogen and oxygen species in the $A \beta$-mediated inhibition of LTP induction. Our studies show that the $A \beta$-mediated inhibition of LTP induction involves activation of microglia and also inducible nitric oxide synthase (iNOS) and superoxide, with toxicity produced possibly via peroxynitrite production.

\section{Materials and Methods}

Preparation of slices. All experiments were performed on transverse slices of the rat hippocampus (males, age 3-4 weeks, weight 40-80 gm) or 
mice aged 3-4 months. Male wild-type and iNOS knock-out C57 black mice (18-28 gm) were obtained from Jackson Laboratories (Bar Harbor, ME). The brains were removed rapidly after decapitation and placed in cold, oxygenated $\left(95 \% \mathrm{O}_{2} / 5 \% \mathrm{CO}_{2}\right)$ medium. Slices were cut at a thickness of $350 \mu \mathrm{m}$, using a Campden Vibroslice, and placed in a storage container containing oxygenated medium at room temperature $\left(20-22^{\circ} \mathrm{C}\right)$ for $1 \mathrm{hr}$. Then the slices were transferred to a recording chamber for submerged slices and superfused continuously at a rate of $5-6 \mathrm{ml} / \mathrm{min}$ at $30-32^{\circ} \mathrm{C}$. The control medium contained (in $\mathrm{mM}$ ): $120 \mathrm{NaCl}, 2.5 \mathrm{KCl}$, $1.25 \mathrm{NaH}_{2} \mathrm{PO}_{4}, 26 \mathrm{NaHCO}_{3}, 2.0 \mathrm{MgSO}_{4}, 2.0$ $\mathrm{CaCl}_{2}, 10$ D-glucose. For experiments on the dentate gyrus all solutions contained $100 \mu \mathrm{M}$ picrotoxin (Sigma, St. Louis, MO) to block $\mathrm{GABA}_{\mathrm{A}}$-mediated activity.

Agents. Drugs used were A $\beta$ (Bachem, Torrance, $\mathrm{CA}$ ), minocycline, aminoguanidine, superoxide dismutase, diphenyleneiodonium (DPI), catalase, D (-)-2-amino-5-phosphonopentanoic acid (D-AP-5) (all from Sigma), and 1400W (Calbiochem, La Jolla, CA). Synthetic A $\beta_{1-42}$ was prepared as a stock solution of $50 \mu \mathrm{M}$ in ammonium hydroxide $(0.1 \%)$, stored at $-20^{\circ} \mathrm{C}$, and then added to physiological medium immediately before each experiment. $A \beta$ was perfused for $40 \mathrm{~min}$ before high-frequency stimulation (HFS)-induced LTP. The other agents were prepared in distilled water. Perfusion of drugs was started 60 min before HFS.

Electrophysiological techniques. Standard electrophysiological techniques were used to record field potentials. All experiments investigating NMDA receptor-dependent (NMDARdependent) LTP and long-term depression (LTD) were performed in the dentate gyrus, with presynaptic stimulation applied to the medial perforant pathway of the dentate gyrus by using a bipolar insulated tungsten wire electrode; field EPSPs were recorded at a control test frequency of $0.033 \mathrm{~Hz}$ from the middle onethird of the molecular layer of the dentate gyrus with a glass microelectrode. In each experiment, an input-output curve (afferent stimulus intensity vs EPSP amplitude) was plotted at the test frequency. For all experiments the amplitude of the test EPSP was adjusted to one-third of maximum $(\sim 1.2 \mathrm{mV})$. LTP was evoked by HFSs consisting of eight trains, each of eight stimuli at $200 \mathrm{~Hz}$, and an intertrain interval of $2 \mathrm{sec}$, with the stimulation voltage increased during the HFS so as to elicit an initial EPSP of the train of double the normal test EPSP amplitude. The experiments investigating NMDAR-independent LTP were performed in the CA1 region, with NMDAR-independent LTP induced by three spaced HFSs at 10 min intervals, each HFS as above. Measurements of resting potential and input resistance were performed with whole-cell patch-clamp recordings from CA1 pyramidal cells by using the Axopatch 1D amplifier (3 kHz low-pass Bessel filter). Series resistance varied from 15 to $30 \mathrm{M} \Omega$.

In experiments involving the application of $\mathrm{A} \beta, \mathrm{A} \beta$ was perfused for $40 \mathrm{~min}$ before HFS. In experiments involving additional other agents, the agents were perfused over the slices for $60 \mathrm{~min}$ before HFS. Control (vehicle alone) and experimental levels of LTP were measured on slices prepared from the same hippocampus. In experiments involving kinase inhibitors, the effect of kinase inhibitor alone and the effects of the kinase inhibitor applied together with $\mathrm{A} \beta$ also were performed on slices from the same hippocampus.

Recordings were analyzed with pClamp (Axon Instruments, Foster
City, CA). Values are the means \pm SEM for $n$ slices. Two-tailed Student's $t$ test and two-way ANOVA with repeated measures were used for statistical comparison.

\section{Results}

\section{$A \beta$ inhibits induction of NMDAR-dependent LTP}

In rat hippocampal slices, HFS induced NMDAR-dependent LTP under control conditions that reached a peak amplitude of $\sim 100 \%$ above baseline immediately after HFS and then slowly declined over the next hour to $50-80 \%$ above baseline. The averaged LTP measured $213 \pm 16$ and $162 \pm 4 \%$ at peak and $60 \mathrm{~min}$ post-HFS, respectively ( $p<0.005 ; n=15)$ (Fig. $1 A$ ).

In a recent study, we showed that synthetic $A \beta$ inhibited the induction of NMDAR-dependent LTP in vitro, with a threshold concentration of $\mathrm{A} \beta$ of $100-200 \mathrm{nM}$ and a strong inhibition by $500 \mathrm{~nm} \mathrm{~A} \beta$ (Wang et al., 2004). In the present study, we have used a concentration of $500 \mathrm{~nm} \mathrm{~A} \beta$ for all experiments on NMDARdependent LTP. Perfusion of A $\beta$ ( $500 \mathrm{~nm}$ ) did not alter the membrane potential nor input resistance measured under whole-cell current-clamp conditions. The mean resting potential and input 
resistance were $-71 \pm 8 \mathrm{mV}$ and $239 \pm 14 \mathrm{M} \Omega$ in control and $-69 \pm 4 \mathrm{mV}$ and $234 \pm 8 \mathrm{M} \Omega$ after perfusion of $\mathrm{A} \beta$ for $60 \mathrm{~min}$ $(p>0.05 ; n=4)$. Moreover, $\mathrm{A} \beta(500 \mathrm{~nm})$ did not affect baseline excitatory synaptic transmission, EPSPs measuring $99 \pm 3 \%$ of control after $40 \mathrm{~min}$ of perfusion ( $p>0.05 ; n=6)$. However, $\mathrm{A} \beta$ (500 nM) perfused for 40 min before HFS strongly inhibited the induction of LTP. In an initial series of experiments, LTP measured $153 \pm 14$ and $107 \pm 5 \%$ at peak and 60 min post-HFS, respectively $(p<0.005 ; n=6)$ (Fig. $1 A$ ). A two-way ANOVA comparing LTP in control and in A $\beta$ also showed significant inhibition $(F=48.2 ; p<0.001)$. Additional experiments were performed on the effects of $500 \mathrm{~nm} \mathrm{~A} \beta$ on LTP induction throughout the course of the study, with three to four interleaved control experiments on the effect of $\mathrm{A} \beta$ on LTP induction being performed during the investigation of the effect of each agent on the $\mathrm{A} \beta$-mediated block of LTP induction. These experiments showed a very similar inhibitory effect of $A \beta$ on LTP induction to the initial set of experiments, LTP measuring $153 \pm 10$ and $102 \pm$ $7 \%$ at peak and 60 min post-HFS, respectively, in the presence of $\mathrm{A} \beta$, significantly less than control LTP in the absence of $\mathrm{A} \beta(p<$ 0.005; $n=23$ ) (data not shown).

\section{A $\boldsymbol{\beta}$ does not inhibit induction of NMDAR-independent LTP or LTD}

To determine whether the inhibitory action of $A \beta$ was confined to NMDAR-dependent LTP or affected other types of plasticity, we investigated the effect of $A \beta$ on NMDAR-independent LTP and LTD. Although NMDAR-independent LTP can be induced by strong stimulation in the dentate gyrus (Wu et al., 2004), such stimulation commonly results in induction of a group I mGluRdependent LTD (Wu et al., 2004). In the present study, we therefore chose to study NMDAR-independent LTP in CA1, a region in which NMDAR-independent LTP has been studied intensively and found to be dependent on the activation of mGluR and voltage-gated Ca channels (Grover and Teyler, 1990; Cavus and Teyler, 1996; Grover, 1998; Wu et al., 2004). Previously, A $\beta$ has been shown to block induction of NMDAR-dependent LTP in CA1 in a manner identical to that in the dentate gyrus (Cullen et al., 1997; Itoh et al., 1999; Chen et al., 2000; Vitolo et al., 2002; Walsh et al., 2002).

$\mathrm{A} \beta(1 \mu \mathrm{M})$ did not inhibit NMDAR-independent LTP, recorded in the presence of $100 \mu \mathrm{M}$ D-AP-5 to prevent NMDAR activation. In control, HFS induced NMDAR-independent LTP, measuring $158 \pm 16$ and $136 \pm 7 \%$ at peak and at $60 \mathrm{~min}$ postHFS, respectively, values showing significant LTP $(p<0.005$; $n=15$ ) (Fig. $1 B$ ). In the presence of $\mathrm{A} \beta$, perfused for $40 \mathrm{~min}$ before HFS, LTP measured $144 \pm 15$ and $129 \pm 3 \%$ at peak and $60 \mathrm{~min}$ post-HFS, respectively, values not significantly reduced from control ( $p>0.05 ; n=5)$. A two-way ANOVA also showed no significant inhibition $(F=4.6 ; p=0.076)$.

We also investigated the effect of $A \beta$ on an additional form of plasticity, that of LTD. Induction of LTD by LFS (900 stimuli at 1 $\mathrm{Hz}$ ) was not affected by $\mathrm{A} \beta$, with LTD at 60 min post-LFS measuring $23 \pm 3 \%$ in control and $21 \pm 2 \%$ after $A \beta$ perfusion for 40 $\min (p>0.05 ; n=5)$ (Fig. $1 C)$. A two-way ANOVA also showed no significant inhibition $(F=4.3 ; p=0.071)$.

\section{Inhibition of microglia activation prevents $\mathrm{A} \beta$ inhibition of LTP}

Several neurochemical studies have reported that the neurotoxic effects of $A \beta$ are mediated via activation of microglia (McDonald et al., 1997; Minghetti and Levi, 1998; Tan et al., 1999). Minocycline is a tetracycline derivative that has powerful anti-

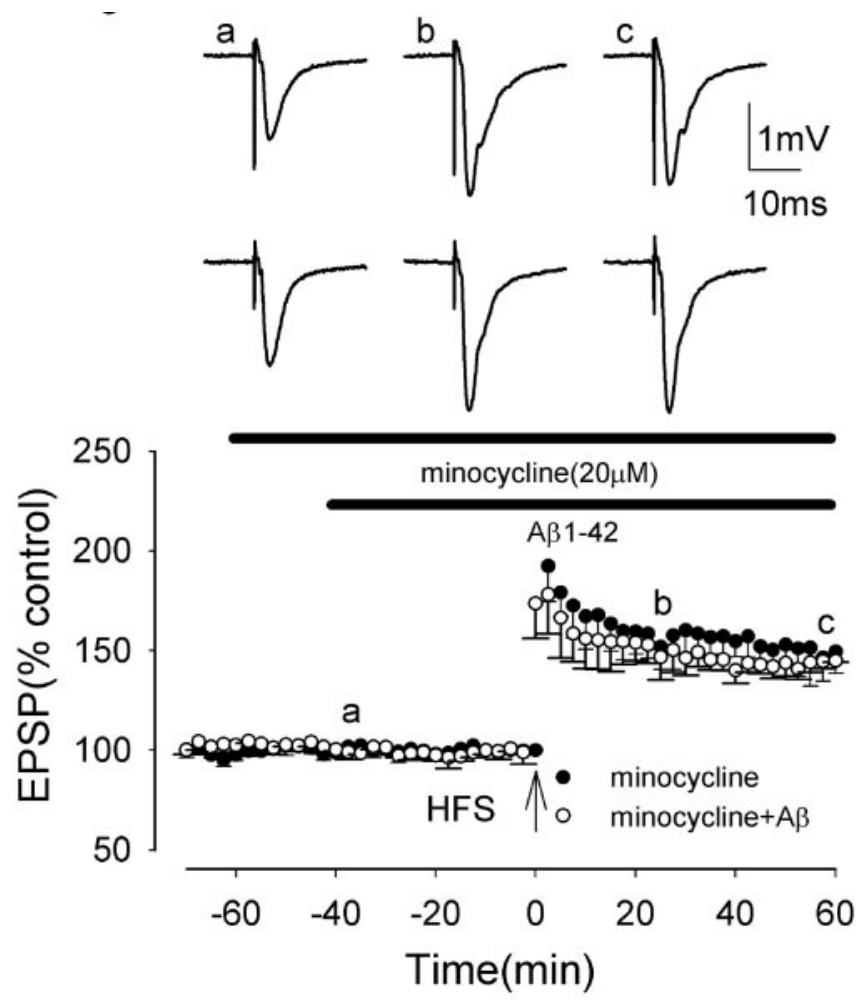

Figure 2. Minocycline, an inhibitor of microglial activation, prevents the $A \beta$-mediated inhibition of LTP induction in the medial perforant path of the rat dentate gyrus in vitro. The graph shows the induction of LTP in the presence of minocycline (filled circles), not significantly different from control LTP, and in the presence of minocycline plus $A \beta$ (open circles). Minocycline prevented the $A \beta$-mediated inhibition of LTP induction. All data shown are the means \pm SEM. The traces $a-c$ are the field EPSPs at the times indicated on the graph, with the top traces showing controls and the bottom traces showing the effect of $A \beta$.

inflammatory effects that are not attributable to its antimicrobial action but, rather, are attributable to inhibition of microglial activation (Yrjanheikki et al., 1998; Tikka et al., 2001; Zhu et al., 2002). To determine whether the $A \beta$-mediated inhibition of LTP induction involves activation of microglia, we have determined whether minocycline prevents such $\mathrm{A} \beta$-mediated LTP inhibition.

Minocycline was perfused for 60 min before HFS. Minocycline $(20 \mu \mathrm{M})$ perfused alone did not alter LTP induction, which measured $204 \pm 19$ and $149 \pm 11 \%$ at peak and $60 \mathrm{~min}$ post-HFS, respectively ( $p>0.05 ; n=5$ ) (Fig. 2 ). A two-way ANOVA showed no significant difference between LTP in control and in minocycline $(F=0.9 ; p=0.37)$. However, minocycline reversed the $\mathrm{A} \beta$ inhibition of LTP induction, LTP measuring $186 \pm 23$ and $145 \pm 1 \%$ at peak and 60 min post-HFS, respectively, in minocycline plus $A \beta$. These values were not significantly different from control values ( $p>0.05 ; n=5$ ) (Fig. 2). A two-way ANOVA comparing LTP in control and in $\mathrm{A} \beta$ also showed no significant difference between LTP in minocycline and in minocycline plus $\mathrm{A} \beta(F=13.6 ; p>0.05)$. A significant reversal of $\mathrm{A} \beta$-mediated block of LTP also was obtained by using a lower concentration of minocycline $(10 \mu \mathrm{M})$, LTP measuring $177 \pm 5$ and $126 \pm 5 \%$ at peak and 60 min post-HFS, respectively, in minocycline plus $A \beta$, values significantly increased from those in $\mathrm{A} \beta$ alone $(p<0.005 ; n=5)$ (data not shown).

A $\boldsymbol{\beta}$ does not inhibit LTP induction in iNOS knock-out mice Microglia are known to produce NO during inflammation by activation of the enzyme iNOS (Akama and Van Eldik, 2000), and 
increased levels of iNOS occur in cells surrounding amyloid plaques in the $\mathrm{AD}$ brain (Smith et al., 1997). Moreover, A $\beta$ causes iNOS production in glia cells (Akama and Van Eldik, 2000). In the present study, we investigated the role of iNOS in the $\mathrm{A} \beta$ mediated inhibition of LTP induction by examining the effects of $\mathrm{A} \beta$ on LTP induction in iNOS mutant mice.

The effects of $\mathrm{A} \beta$ on LTP induction was investigated first in wild-type mice. Control LTP induction in wild-type mice was similar to that in juvenile rats, measuring $216 \pm 21$ and $165 \pm 13 \%$ at peak and 60 min post-HFS, respectively (significant LTP; $p<0.005$; $n=15$ ) (Fig. $3 A$ ). Moreover, $\mathrm{A} \beta$, perfused $45 \mathrm{~min}$ before HFS, inhibited LTP induction in a similar way to that observed in rats, with LTP measuring $163 \pm 7$ and $110 \pm 16 \%$ at peak and $60 \mathrm{~min}$ post-HFS, respectively $(p<0.005 ; n=$ 15) (Fig. $3 A$ ). A two-way ANOVA comparing LTP in control and in $\mathrm{A} \beta$ also showed significant inhibition of LTP by A $\beta(F=43.1 ; p<0.001)$.

Control LTP in iNOS mutant mice was not significantly different from that in wild-type mice, measuring $222 \pm 13$ and $171 \pm 9 \%$ at peak and 60 min post-HFS, respectively $(p>0.05 ; n=5 ; F=1.5 ; p=$ 0.26 ) (Fig. $3 B$ ). However, in contrast to wild-type mice, LTP induction was not inhibited by $\mathrm{A} \beta$ (500 nM), LTP measuring $216 \pm 18$ and $152 \pm 11 \%$ at peak and 60 min post-HFS, respectively $(p>0.05 ; n=$ 5) (Fig. 3B). A two-way ANOVA comparing LTP in the presence of $A \beta$ in wild-type mice and iNOS mutant mice showed significant difference $(F=40.7 ; p<0.001)$.

These experiments demonstrate a role for iNOS in the $\mathrm{A} \beta$-mediated inhibition of LTP induction.

\section{$A \beta$-mediated inhibition of LTP induction is prevented by iNOS inhibitors}

To investigate further the role of iNOS in the $\mathrm{A} \beta$-mediated inhibition of LTP induction, we investigated the effect of NOS inhibitors on the $\mathrm{A} \beta$-mediated inhibition of LTP in rat dentate gyrus. We first investigated the effects of aminoguanidine, which is known to inhibit both constitutive and inducible NOS isoforms (Laszlo et al., 1995). In control slices, aminoguanidine $(100 \mu \mathrm{M})$ did not alter control LTP induction, which measured $221 \pm 14$ and $170 \pm 3 \%$ at peak and $60 \mathrm{~min}$ post-HFS, respectively ( $p<0.05 ; n=5 ; F=0.1 ; p=0.76$ ) (Fig. $4 A)$. However, the $\mathrm{A} \beta$-mediated inhibition of LTP induction was prevented by aminoguanidine, LTP measuring $203 \pm 12$ and $143 \pm 11 \%$ at peak and $60 \mathrm{~min}$ post-HFS, respectively, in the presence of $\mathrm{A} \beta$ and aminoguanidine. These values were not significantly different from control values $(p>0.05 ; n=5)$ (Fig. $4 A$ ) but were increased significantly from the values in $\mathrm{A} \beta$ alone $(p<0.005 ; n=5 ; F=67.4 ; p<0.001)$.
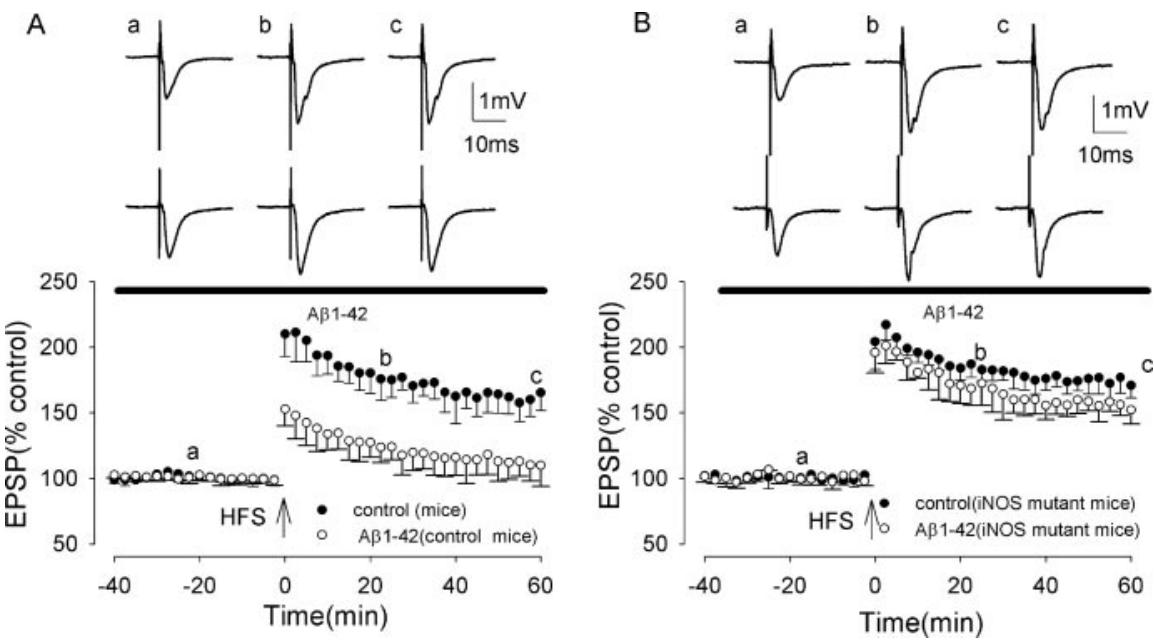

Figure 3. $A \beta$ does not inhibit LTP in iNOS knock-out mice. $A$, Induction of LTP in the medial perforant path of the dentate gyrus of wild-type mice (filled circles) and in wild-type mice plus $A \beta$ (open circles). $A \beta$ inhibited LTP induction in the mouse dentate gyrus to an extent similar to that in the rat dentate gyrus. $B$, Induction of LTP in iNOS knock-out mice (filled circles), not signifisignificantly different from control. All data shown are the means \pm SEM. The traces $a-c$ are the field EPSPs at the times indicated on the graph, with the top traces showing controls and the bottom traces showing the effect of $A \beta$.
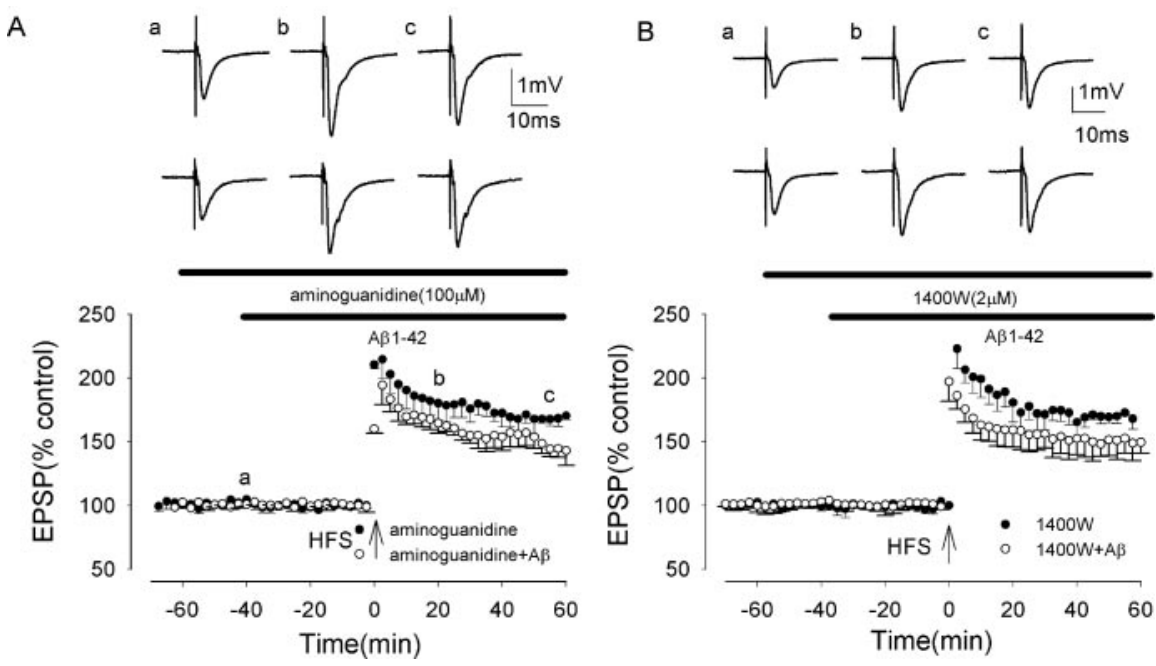

Figure 4. The $A \beta$-evoked inhibition of LTP induction is prevented by the iNOS inhibitors aminoguanidine and $1400 \mathrm{~W}$ in the medial perforant path of the rat dentate gyrus. $A$, Induction of LTP in the presence of aminoguanidine (filled circles), not signifi$A \beta$-mediated inhibition of LTP induction. $B$, Induction of LTP in the presence of $1400 \mathrm{~W}$ (filled circles), not significantly reduced from control, and in the presence of $1400 \mathrm{~W}$ plus $A \beta$ (open circles). $1400 \mathrm{~W}$ prevented the $A \beta$-mediated inhibition of LTP induction. All data shown are the means \pm SEM. The traces $a-c$ are the field EPSPs at the times indicated on the graph, with the top traces showing controls and the bottom traces showing the effect of $A \beta$.

We then investigated the effects of the selective iNOS inhibitor $1400 \mathrm{~W} .1400 \mathrm{~W}$ is a selective iNOS inhibitor, $K_{\mathrm{D}}=7 \mathrm{nM}$, with a 5000 - and 200-fold greater potency against iNOS relative to endothelial NOS and neuronal NOS (Garvey et al., 1997). In control slices, 1400W $(2 \mu \mathrm{M})$ did not alter control LTP induction, which measured $223 \pm 17$ and $167 \pm 5 \%$ at peak and 60 min post-HFS, respectively (significant LTP; $p<0.001 ; n=5$ ) (Fig. $4 B$ ). A two-way ANOVA showed no significant difference between LTP in control and in 1400W, $F$ value $=1.4(p=0.246)$. However, the $\mathrm{A} \beta$-mediated inhibition of LTP induction was prevented by $1400 \mathrm{~W}$, LTP measuring $199 \pm 8$ and $150 \pm 8 \%$ at peak and 60 min post-HFS in the presence of $\mathrm{A} \beta$ and $1400 \mathrm{~W}$, respectively. These values were not significantly different from control values 
A
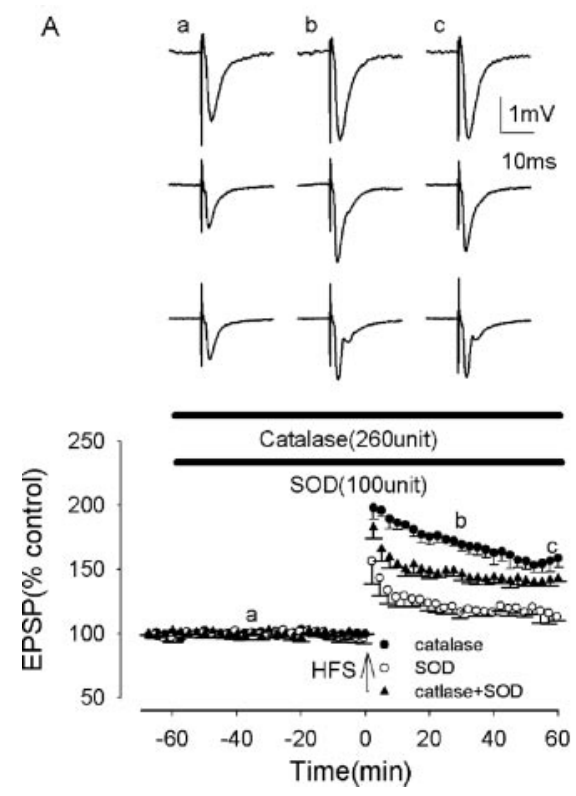

B

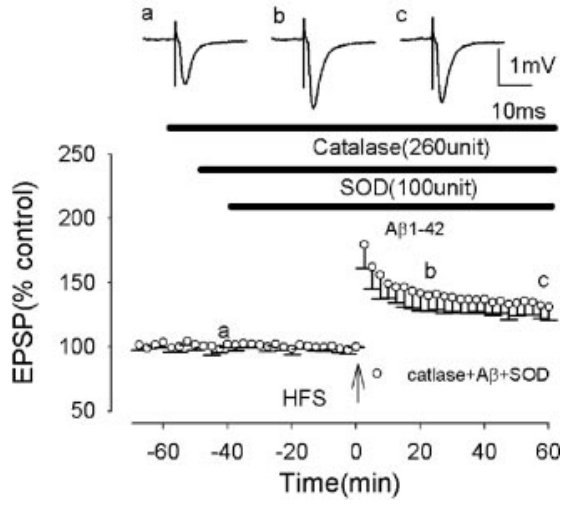

Figure 5. The $A \beta$-evoked inhibition of $L T P$ induction is prevented by the superoxide scavenger $S O D$ in rat slices. $A$, Induction of LTP in the presence of SOD (open circles), significantly reduced from control; in the presence of catalase (filled circles), not significantly reduced from control; and in the presence of SOD plus catalase, partially reduced from control. $B, L T P$ induction in the presence of SOD plus catalase plus A $\beta$. The combination of SOD plus catalase prevented the $A \beta$-mediated inhibition of LTP induction. All data shown are the means \pm SEM. The traces $a-c$ are the field EPSPs at the times indicated on the graph, with the traces in $A$ showing controls (catalase, SOD, and catalase plus SOD from top to bottom) and the traces in $B$ showing catalase plus SOD plus $A \beta$.

$(p>0.05 ; n=5)($ Fig. $4 B)$ but were increased significantly from the values in $\mathrm{A} \beta$ alone $(p<0.005 ; n=5 ; F=21.6 ; p<0.002)$. The results of these experiments with aminoguanidine and 1400W further support a role for iNOS in $\mathrm{A} \beta$-mediated inhibition of LTP induction.

\section{A $\beta$-mediated inhibition of LTP induction is prevented by a combination of superoxide dismutase and catalase}

To investigate the role of the reactive oxygen species (ROS) superoxide, we examined the effect of the superoxide scavenger superoxide dismutase (SOD) on A $\beta$-mediated inhibition of LTP induction. SOD is a specific enzyme that catalyzes only the removal of superoxide (Klann et al., 1998). In confirmation of previous studies (Klann et al., 1998), SOD applied alone inhibited LTP induction. Thus in the presence of SOD (100 U/ml) LTP measured $160 \pm 17$ and $116 \pm 5 \%$ at peak and $60 \mathrm{~min}$ post-HFS, respectively $(p<0.005 ; n=5 ; F=80.6 ; p<0.001)$ (Fig. $5 A$ ). Such inhibition of LTP induction by SOD is most likely to be caused by hydrogen peroxide production, because SOD converts superoxide to oxygen and hydrogen peroxide, and the latter species is known to inhibit LTP induction (Kamsler and Segal, 2003). To overcome these effects of hydrogen peroxide on LTP induction, we examined the effects of $\mathrm{A} \beta$ on LTP induction in the presence of SOD plus catalase. Catalase is a scavenger of hydrogen peroxide, catalyzing its conversion to oxygen and water. Catalase alone $(260 \mathrm{U} / \mathrm{ml})$ did not alter LTP induction, which measured $203 \pm 11$ and $169 \pm 7 \%$ at peak and at 20 and $60 \mathrm{~min}$ post-HFS, respectively ( $p>0.05 ; n=5$ ) (Fig. $5 B$ ). However, catalase prevented the inhibitory effects of SOD on LTP induction, LTP measuring $197 \pm 12$ and $142 \pm 6 \%$ at peak and $60 \mathrm{~min}$ post-HFS in catalase plus SOD, respectively, values significantly increased from those in SOD alone $(p<0.005 ; n=5)$, although lower than control $(p<0.005 ; n=5)$.

The combination of SOD plus catalase was found to prevent the $\mathrm{A} \beta$-mediated inhibition of LTP induction, LTP measuring $194 \pm 20$ and $131 \pm 10 \%$ at peak and 60 min post-HFS, respectively, in the presence of $\mathrm{A} \beta$ plus SOD plus catalase. These values were increased significantly from the values in $\mathrm{A} \beta$ alone $(p<0.005 ; n=5$; $F=59.4 ; p<0.001$ ) (Fig. $5 B$ ), although lower than control values $(p<0.005 ; n=$ 5 ). These experiments demonstrate a role for superoxide in the $\mathrm{A} \beta$-mediated inhibition of LTP induction.

\section{A $\beta$-mediated inhibition of LTP induction is prevented by an inhibitor of NADPH oxidase}

NADPH oxidase is a common source of superoxide in cells, with activated NADPH catalyzing the transfer of one electron from NADPH to oxygen, giving rise to superoxide. DPI is an inhibitor that has been used in many studies to prevent the production of superoxide by NADPH oxidase (Qin et al., 2002). DPI (50 $\mu \mathrm{M})$ did not inhibit LTP induction, which measured $212 \pm 17$ and $167 \pm 6 \%$ at peak and $60 \mathrm{~min}$ post-HFS, respectively $(p>0.05 ; n=5$; $F=0.13 ; p=0.73$ ) (Fig. 6). However, DPI partially prevented the $\mathrm{A} \beta$-mediated block of LTP induction, LTP measuring $180 \pm 15$ and $146 \pm 7 \%$ at peak and $60 \mathrm{~min}$ post-HFS, respectively, in the presence of DPI plus $\mathrm{A} \beta$. These values were not significantly different from control values ( $p>0.05 ; n=5$ ) (Fig. 6 ) but were increased significantly from the values in $\mathrm{A} \beta$ alone $(p<0.005 ; F=26.1 ; p<0.001)$.

\section{Discussion}

This study demonstrates that a low concentration of $A \beta$ inhibits NMDAR-dependent LTP induction, confirming previous studies from our laboratory in CA1 in vivo and dentate gyrus in vitro (Cullen et al., 1997; Wang et al., 2004) and several other studies in CA1 and dentate gyrus in vitro (Lambert et al., 1998; Itoh et al., 1999; Chen et al., 2000; Stephan et al., 2001; Vitolo et al., 2002; Raymond et al., 2003). The lack of effect of $A \beta$ on membrane potential, input resistance, and baseline EPSPs demonstrates that $\mathrm{A} \beta$ does not cause a general deleterious effect on cell viability or on inhibition of AMPA receptors contributing to baseline EPSPs. The inhibitory effect of $A \beta$ was found to be confined to a specific plasticity, that of the induction of NMDAR-dependent LTP. Thus $\mathrm{A} \beta$ did not inhibit the induction of NMDAR-independent LTP or of LTD, the latter observations in agreement with Wang et al. (2002) and Raymond et al. (2003). Such a selective action of $\mathrm{A} \beta$ on induction of plasticity suggests that $\mathrm{A} \beta$ inhibits a specific process essential to induction of NMDAR-dependent LTP. It is unlikely that $A \beta$ results in inhibition of LTP via a block of activation of NMDAR, because $A \beta$ produces only a very small inhibition of NMDAR-mediated EPSPs, which is insufficient to reduce the induction of LTP (Raymond et al., 2003). However, NMDAR-dependent LTP is well known to involve activation of calcium/calmodulin kinase II (CaMKII) (for review, see Lisman et al., 2002) in contrast to that of NMDAR-independent LTP, which is independent of the activation of CaMKII (Cavus and 


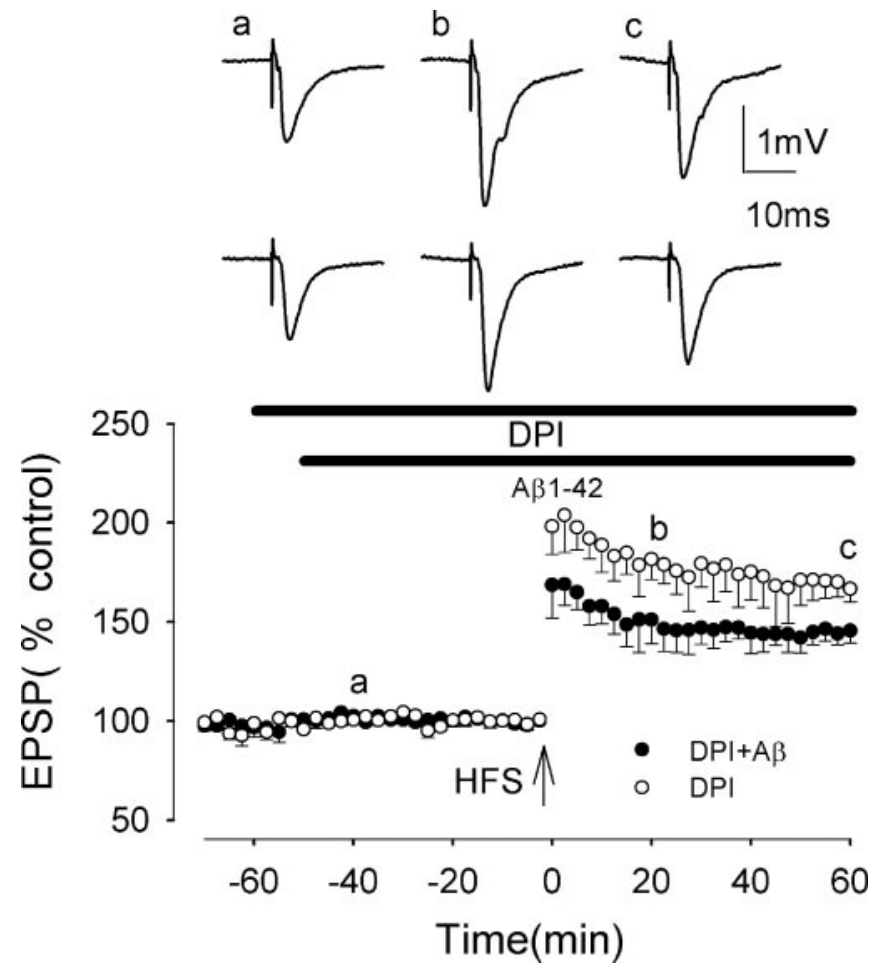

Figure 6. The $A \beta$-evoked inhibition of LTP induction is prevented by the NADPH oxidase inhibitor diphenyleneiodonium (DPI) in rat slices. The graph shows that DPI partially prevents the $A \beta$-mediated inhibition of LTP induction (filled circles). All data shown are the means \pm SEM. The traces $a-$ c are the field EPSPs at the times indicated on the graph, with the top traces showing controls and the bottom traces showing the effect of $A \beta$.

Teyler, 1996). This suggests the possibility that receptor binding of $\mathrm{A} \beta$ may result in a block of the activation of CaMKII.

Accumulating experimental evidence suggests a causal link among $\mathrm{A} \beta$, oxidative stress, and $\mathrm{AD}$. The present studies provide similar links among $\mathrm{A} \beta$, oxidative stress, and the inhibition of LTP. We provide evidence that the $\mathrm{A} \beta$-mediated inhibition of LTP induction involves activation of microglia, the principle immune effector cell in the brain. This conclusion is based on the results of our studies with minocycline, a tetracycline inhibitor of microglial activation, which was found to prevent the action of $\mathrm{A} \beta$ in blocking induction of LTP. Although minocycline has not been reported previously to prevent the microglial activation produced by $\mathrm{A} \beta$, it has marked in vivo neuroprotective properties in experimental models of neurodegeneration, including cerebral ischemia, traumatic brain injury, Huntington's disease, Parkinson's disease and amyotrophic lateral sclerosis (Yrjanheikki et al., 1998; Chen et al., 2000; Du et al., 2001; Sanchez Mejia et al., 2001; Zhu et al., 2002). Minocycline also has been found to be neuroprotective in a variety of in vitro models of cell death, with a rapid action similar to that observed in the present studies on LTP. For example, $30 \mathrm{~min}$ preapplication of minocycline to spinal cord cultures inhibited the rapid (10 $\mathrm{min}$ ) excitotoxin-induced effects of excitatory amino acids (Tikka et al., 2001). Zhu et al. (2002) also showed a rapid protective effect of minocycline against NMDAR-mediated cell death in acute studies in primary cortical neurons. The mechanisms of action of minocycline underlying its neuroprotective effect include inhibition of cytochrome $c$ release, caspases, and p38 MAPK (Yrjanheikki et al., 1998; Tikka et al., 2001; Zhu et al., 2002). Interestingly, in a recent study we showed that activation of $38 \mathrm{MAPK}$ is required for $\mathrm{A} \beta$-mediated inhibition of LTP induction (Wang et al., 2004).
The finding of an involvement of microglia in $A \beta$-mediated inhibition of LTP supports previous evidence for an involvement of microglia in $\mathrm{AD}$. The pathology of $\mathrm{AD}$ has been well documented to involve a chronic inflammatory reaction driven by activated microglia (Griffin et al., 1998; Akiyama et al., 2000); abundant reactive microglia surround $\beta$-amyloid plaques in the AD brain (McGeer and McGeer, 1995; Cotman and Su, 1996), and treatment with anti-inflammatory agents has been correlated with a large reduction in plaque-associated reactive microglia and a decrease in severity of AD (MacKenzie and Munoz, 1998). In addition, $\mathrm{A} \beta$ causes activation of microglia cells in culture (Tan et al., 1999; Akiyama et al., 2000; Combs et al., 2000; Bamberger et al., 2003), and activated microglial cells have been shown to be the link between $\mathrm{A} \beta$ deposition and neuronal death (Eikelenboom et al., 1994; McGeer and McGeer, 1995).

Evidence for a requirement for activation of iNOS in the $\mathrm{A} \beta$ mediated inhibition of LTP induction was found in the present study via the use of iNOS mutant mice and two selective inhibitors of iNOS, aminoguanidine and 1400W. Increased levels of iNOS have been found in cells surrounding amyloid plaques (Wallace et al., 1997), and A $\beta$ can stimulate iNOS in microglia in vitro and in vivo (Akama et al., 1998; Akama and Van Eldik, 2000). Stimulation of iNOS catalyzes the oxidation of L-arginine to L-citrulline and nitric oxide. Although nitric oxide is a free radical, the main cytotoxic action of NO is most likely attributable to production of peroxynitrite (see below).

Evidence was presented in the present study for the involvement of superoxide in the A $\beta$-mediated inhibition of LTP induction. Thus a combination of the superoxide scavenger SOD and the hydrogen peroxide scavenger catalase prevented the $\mathrm{A} \beta$ mediated inhibition of LTP induction. Moreover, inhibition of NADPH oxidase by DPI was found to prevent the $\mathrm{A} \beta$-mediated inhibition of LTP induction. Activation of NADPH oxidase has been shown previously to be a major source of superoxide production involved in $A \beta$-induced toxicity (Bianca et al., 1999), and the $\mathrm{A} \beta$-induced production of superoxide was blocked by the NADPH oxidase inhibitor DPI (Qin et al., 2002). We postulate that the active cytotoxic species responsible for the $\mathrm{A} \beta$ mediated block of LTP is most likely to be peroxynitrite, formed by the combination of NO and superoxide (Lipton et al., 1993). The reaction between superoxide and nitric oxide to produce peroxynitrite is very rapid and out-competes the major scavenging pathways for nitric oxide and superoxide. Peroxynitrite is a highly reactive strong oxidant and nitrating agent and is known to cause neuronal death in cultured cells (Lin et al., 1998).

The data presented in this paper and that of Wang et al. (2004) demonstrate that $\mathrm{A} \beta$ causes inhibition of LTP induction by a series of events. We suggest that $\mathrm{A} \beta$ initially activates a receptor, which could be a scavenger receptor (El Khoury et al., 1996), a receptor for advanced glycation end products (Yan et al., 1996), a receptor complex including a scavenger and integrin proteins (Bamberger et al., 2003), or the tumor necrosis factor type I receptor (TNFRI) (Li et al., 2004). The latter possibility is particularly intriguing because soluble $\mathrm{A} \beta$, the species known to be active in inhibiting LTP, has been found to bind potently to TNFRI (Li et al., 2004). We show that microglial activation leads to production of NO and superoxide, which then react to form peroxynitrite. Peroxynitrite probably results in the inhibition of LTP via oxidation/tyrosine nitration of a particular protein necessary for LTP induction. We recently demonstrated an essential role for $\mathrm{p} 38$ and JNK activation in the A $\beta$-mediated inhibition of LTP (Wang et al., 2004). Activated p38 MAPK and JNK have been immunolocalized to microglia associated with amyloid plaques 
in the AD brain (Hensley et al., 1999), and they are well known to be activated by oxidative stress (Cobb, 1999) and to be linked to production of iNOS and superoxide. For example, it has been reported that $\mathrm{p} 38$ MAPK is involved in iNOS and peroxynitrite activation in glial cells (Da Silva et al., 1997). It is particularly interesting that inflammatory factors and reactive oxygen/nitrogen species that have been associated in previous studies with $A \beta$-mediated neuronal degeneration have been shown in the present study to be associated with $\mathrm{A} \beta$-mediated inhibition of LTP induction after a very short exposure $(\sim 30 \mathrm{~min})$ to $A \beta$. Thus the presence of excess levels of $A \beta$ in humans may result in a very rapid inhibition of LTP and thence cognitive defects.

How might an oxidative/inflammatory-like block of LTP by $\mathrm{A} \beta$ help explain the pathophysiology and symptoms of AD? Several theories of $\mathrm{AD}$ have implicated $\mathrm{A} \beta$-triggered oxidative/ inflammatory-like effects in the development of the disease (for review, see McGeer and McGeer, 2003). Moreover, previous studies have presented strong evidence that synapses are the initial target in AD (for review, see Selkoe, 2002). The hippocampus is especially vulnerable in $\mathrm{AD}$, and early debilitating symptoms usually include significant deficits in the performance of hippocampus-dependent cognitive tasks. Given the evidence that LTP underlies hippocampus-dependent learning and memory (Martin and Morris, 2002), the present findings of a block of LTP by $\mathrm{A} \beta$ provide a plausible mechanism for the impairment of cognitive functions in $\mathrm{AD}$, especially early in the disease process. In addition, because plasticity at synapses is important for their survival (Toni et al., 1999; Hering and Sheng, 2001), any persistent disruption of LTP induction mechanisms may provide a very sensitive predictor of synaptic vulnerability to degeneration.

\section{References}

Akama KT, Van Eldik LJV (2000) $\beta$-Amyloid stimulation of inducible nitric oxide synthase in astrocytes is IL- $1 \beta$ - and TNF- $\alpha$-dependent. J Biol Chem 275:7918-7924.

Akama KT, Albanese C, Pestell RG, Van Eldik LJ (1998) Amyloid $\beta$-peptide stimulates nitric oxide production in astrocytes through an NF- $\kappa \mathrm{B}-$ dependent mechanism. Proc Natl Acad Sci USA 95:5795-5800.

Akiyama H, Barger S, Barnum S, Bradt B, Bauer J, Cole GM, Cooper NR, Eikelenboom P, Emmerling M, Fiebich BL, Finch CE, Frautschy S, Griffin WS, Hampel H, Hull M, Landreth G, Lue L, Mrak R, MacKenzie IR, McGeer PL, et al. (2000) Inflammation and Alzheimer's disease. Neurobiol Aging 21:383-421.

Bamberger ME, Harris ME, McDonald DR, Husemann J, Landreth GE (2003) A cell surface receptor complex for fibrillar $\beta$-amyloid mediates microglial activation. J Neurosci 23:2665-2674.

Bianca VD, Dusi S, Bianchini E, Dal Pra I, Rossi F (1999) Beta-amyloid activates the O-2 forming NADPH oxidase in microglia, monocytes, and neutrophils. A possible inflammatory mechanism of neuronal damage in Alzheimer's disease. J Biol Chem 274:15493-15499.

Cavus I, Teyler T (1996) Two forms of long-term potentiation in area CA1 activate different signal transduction cascades. J Neurophysiol 76:30383047.

Chen Q, Kagan BL, Hirajura Y, Xie C (2000) Impairments of hippocampal long-term potentiation by Alzheimer $\beta$-peptide. J Neurosci Res 60:65-72.

Cobb MH (1999) MAP kinase pathways. Prog Biophys Mol Biol 71:479500.

Combs CK, Johnson DE, Karlo JC, Cannady SB, Landreth GE (2000) Inflammatory mechanisms in Alzheimer's disease: inhibition of $\beta$-amyloidstimulated proinflammatory responses and neurotoxicity by PPAR- $\gamma$ agonist. J Neurosci 20:558-567.

Cotman CW, Su JH (1996) Mechanisms of neuronal death in Alzheimer's disease. Brain Pathol 4:493-506.

Cullen WK, Suh Y-H, Anwyl R, Rowan MJ (1997) Block of LTP in rat hippocampus in vivo by $\beta$-amyloid precursor protein fragments. NeuroReport 8:3213-3217.

Da Silva J, Pierrat B, Mary JL, Lesslauer W (1997) Blockade of p38 mitogen- activated protein kinase pathway inhibits inducible nitric-oxide synthase expression in mouse astrocytes. J Biol Chem 272:28373-28380.

Du Y, Ma Z, Lin S, Dodel RC, Gao F, Bales KR, Triarhou LC, Chernet E, Perry KW, Nelson DL, Luecke S, Phebus LA, Bymaster FP, Paul SM (2001) Minocycline prevents nigrostriatal dopaminergic neurodegeneration in the MPTP model of Parkinson's disease. Proc Natl Acad Sci USA 98: $14669-14674$.

Eikelenboom P, Zahn SS, van Gool WA, Allsop D (1994) Inflammatory mechanisms in Alzheimer's disease. Trends Pharmacol Sci 15:447-450.

El Khoury J, Hickman SE, Thomas CA, Cao L, Silverstein SC, Loike JD (1996) Scavenger receptor-mediated adhesion of microglia to betaamyloid fibrils. Nature 382:716-719.

Garvey EP, Oplinger JA, Furfine ES, Kiff RJ, Laszlo F, Whittle BJ, Knowles RG (1997) $1400 \mathrm{~W}$ is a slow, tight-binding, and highly selective inhibitor of inducible nitric-oxide synthase in vitro and in vivo. J Biol Chem 272: 4959-4963.

Griffin WS, Sheng JC, Royston MC, Gentleman SM, McKenzie JE, Graham DI, Roberts GW, Mrak RE (1998) Glial-neuronal interactions in Alzheimer's disease: the potential role of a cytokine cycle in disease progression. Brain Pathol 8:65-72.

Grover L (1998) Evidence for postsynaptic induction and expression of NMDA receptor independent LTP. J Neurophysiol 79:1167-1182.

Grover L, Teyler TJ (1990) Two components of long-term potentiation induced by different patterns of afferent activation. Nature 347:477-479.

Hensley K, Floyd RA, Zheng NY, Nael R, Robinson KA, Nguyen X, Pye QN, Stewart CA, Geddes J, Markesbery WR, Patel E, Johnson GV, Bing G (1999) p38 kinase is activated in the Alzheimer's disease brain. J Neurochem 72:2053-2058.

Hering H, Sheng M (2001) Dendritic spines: structure, dynamics, and regulation. Nat Rev Neurosci 2:880-888.

Itoh A, Akaike T, Sokabe M, Nitta A, Nabeshima T (1999) Impairment of long-term potentiation in hippocampal slices of $\beta$-amyloid-infused rats. Eur J Pharmacol 3:167-175.

Kamsler A, Segal M (2003) Paradoxical actions of hydrogen peroxide on long-term potentiation in transgenic superoxide dismutase-1 mice. J Neurosci 23:10359-10367.

Klann E, Robertson ED, Knapp LT, Sweatt JD (1998) A role for superoxide in protein kinase $\mathrm{C}$ activation and induction of long-term potentiation. J Biol Chem 273:4516-4522.

Lambert MP, Barlow AK, Chromy BA, Edwards C, Freed R, Liosatos M, Morgan TE, Rozovsky I, Trommer B, Viola KL, Wals P, Zhang C, Finch CE, Krafft GA, Klein WL (1998) Diffusible nonfibrillar ligands derived from $A \beta 1-42$ are potent central nervous system neurotoxins. Proc Natl Acad Sci USA 95:6448-6453.

Laszlo F, Evans SM, Whittle BJ (1995) Aminoguanidine inhibits both constitutive and inducible nitric oxide synthase isoforms in rat intestinal microvasculature in vivo. Eur J Pharmacol 272:169-175.

Li R, Yang L, Lindholm K, Konishi Y, Yue X, Hampel H, Zhang D, Shen Y (2004) Tumor necrosis factor death receptor signaling cascade is required for amyloid- $\beta$ protein-induced neuron death. J Neurosci 24:1760-1771.

Lin KT, Xue JY, Lin MC, Spokas EG, Sun FF, Wong PY (1998) Peroxynitrite induces apoptosis of HL-60 cells by activation of a caspase- 3 family protease. Am J Physiol 274:C855-C860.

Lipton SA, Choi YB, Pan ZH, Lei SZ, Chen HS, Sucher NJ, Loscalzo J, Singel DJ, Stamler JS (1993) A redox-based mechanism for the neuroprotective and neurodestructive effects of nitric oxide and related nitrosocompounds. Nature 364:626-632.

Lisman J, Schulman H, Cline H (2002) The molecular basis of CaMKII function in synaptic and behavioural memory. Nat Rev Neurosci 3:175-190.

MacKenzie IR, Munoz DG (1998) Nonsteroidal anti-inflammatory use and Alzheimer-type pathology in aging. Neurology 50:986-990.

Martin SJ, Morris RG (2002) New life in an old idea: the synaptic plasticity and memory hypothesis revisited. Hippocampus 12:609-636.

McDonald DR, Brunden KR, Landreth GE (1997) Amyloid fibrils activate tyrosine kinase-dependent signaling and superoxide production in microglia. J Neurosci 17:2284-2288.

McGeer EG, McGeer PL (2003) Inflammatory processes in Alzheimer's disease. Prog Neuropsychopharmacol Biol Psychiatry 27:741-749.

McGeer PL, McGeer EG (1995) The inflammatory response system of the brain: implications for therapy of Alzheimer and other neurodegenerative diseases. Brain Res Rev 21:195-218. 
Minghetti L, Levi G (1998) Microglia as effector cells in brain damage and repair: focus on prostanoids and nitric oxide. Prog Neurobiol 54:99-125.

Qin L, Liu Y, Cooper C, Liu B, Wilson B, Hong J-S (2002) Microglia enhance $\beta$-amyloid peptide-induced toxicity in cortical and mesencephalic neurons by producing reactive oxygen species. J Neurochem 83:973-983.

Raymond CR, Ireland DR, Abraham WC (2003) NMDA receptor regulation by amyloid- $\beta$ does not account for its inhibition of LTP in rat hippocampus. Brain Res 968:263-272.

Sanchez Mejia RO, Ona VO, Li M, Friedlander RM (2001) Minocycline reduces traumatic brain injury-mediated caspase-1 activation, tissue damage, and neurological dysfunction. Neurosurgery 48:1393-1401.

Selkoe DJ (2002) Alzheimer's disease is a synaptic failure. Science 298:789-791.

Small DH, Mok SS, Bornstein JC (2001) Alzheimer's disease and A $\beta$ toxicity: from top to bottom. Nat Rev Neurosci 8:595-598.

Smith MA, Richey-Harris PL, Sayre LM, Beckman JS, Perry G (1997) Widespread peroxynitrite-mediated damage in Alzheimer's disease. J Neurosci 17:2653-2657.

Stephan A, Laroche S, Davis S (2001) Generation of aggregated $\beta$-amyloid in the rat hippocampus impairs synaptic transmission and plasticity and causes memory deficits. J Neurosci 21:5703-5714.

Tan J, Town T, Paris D, Mori T, Suo Z, Crawford F, Mattson MP, Flavell RA, Mullan M (1999) Microglial activation resulting from CD40-CD40L interaction after $\beta$-amyloid stimulation. Science 286:2352-2355.

Tikka T, Fiebich B, Goldsteins G, Keinanen R, Koistinaho J (2001) Minocycline, a tetracycline derivative, is neuroprotective against excitotoxicity by inhibiting activation and proliferation of microglia. J Neurosci 21:2580-2588.

Toni N, Buchs PA, Nikonenko I, Bron CR, Muller D (1999) (1999) LTP promotes formation of multiple spine synapses between a single axon terminal and a dendrite. Nature 402:421-425.

Vitolo OV, Sant'Angelo A, Costanzo V, Battaglia F, Arancio O, Shelanski M (2002) Amyloid $\beta$-peptide inhibition of the PKA/CREB pathway and long-term potentiation: reversibility by drugs that enhance cAMP signaling. Proc Natl Acad Sci USA 99:13217-13221.

Wallace MN, Geddes JG, Farquar DA, Masson MR (1997) Nitric oxide synthase in reactive astrocytes adjacent to $\beta$-amyloid. Exp Neurol 144:266-272.

Walsh DM, Klyubuin I, Fadeeva J, Cullen WK, Anwyl R, Wolfe MS, Rowan MJ, Selkoe DJ (2002) Naturally secreted oligomers of the Alzheimer amyloid $\beta$-protein potently inhibit long-term potentiation in vivo. $\mathrm{Na}$ ture 416:535-539.

Wang H-W, Pasternak JF, Kuo H, Ristic H, Lambert MP, Chromy B, Violoa KL, Klein WL, Stine WB, Krafft GA, Trommer BL (2002) Soluble oligomers of $\beta$ amyloid (1-42) inhibit long-term depression but not longterm depression in the dentate gyrus. Brain Res 924:133-140.

Wang Q, Walsh DM, Rowan MJ, Selkoe DJ, Anwyl R (2004) Block of LTP by naturally secreted and synthetic amyloid $\beta$-peptide in hippocampal slices is mediated via activation of the kinases JNK, Cdk5, and p38 MAPK as well as mGluR5. J Neurosci 24:3370-3378.

Wu J, Rowan MJ, Anwyl R (2004) An NMDAR-independent LTP mediated by group II metabotropic glutamate receptors and p42/44 MAP kinase in the dentate gyrus in vitro. Neuropharmacology 46:311-331.

Yan SD, Chen X, Fu J, Zhu H, Roher A, Slattery T, Morser J, Nawroth P, Stern $D$, Schmidt AM (1996) RAGE and amyloid- $\beta$ peptide neurotoxicity in Alzheimer's disease. J Biol Chem 274:15493-15499.

Yrjanheikki J, Keinnanen R, Pellikka M, Hokfelt T, Koistinaho J (1998) Tetracyclines inhibit microglial activation and are neuroprotective in global brain ischemia. Proc Natl Acad Sci USA 95:15769-15774.

Zhu S, Stavrovskaya IG, Drozda M, Kim BY, Ona V, Li M, Sarang S, Liu AS, Hartley DM, Wu du C, Gullans S, Ferrante RJ, Przedborski S, Kristal BS, Friedlander RM (2002) Minocycline inhibits cytochrome $c$ release and delays progression of amyotrophic lateral sclerosis in mice. Nature 417: $74-78$. 